\title{
Realidad como antropomorfismo
}

Reality as anthropomorphism

\section{Robert SpaemanN}

Ludwig-Maximilians-Universität München

Abstract: The author of this article shows that the existence of things is always corroborated using cognitive criteria. Thus, human knowledge implies an anthropomorphical way of approaching reality.

Keywords: Being, life, subjectivity, anthropomorphism, understanding.
Resumen: El autor de este artículo muestra que la existencia de las cosas siempre está corroborada mediante criterios cognitivos. Así, el conocimiento humano implica una manera antropomórfica de acercarse a la realidad.

Palabras clave: Ser, vida, subjetividad, antropomorfismo, comprensión.

Publicado originalmente en alemán como Wirklichkeit als Anthropomorphismus, en O. G. BAUER (ed.), Was heißßt 'wirklich'? Unsere Erkenntnis zwischen Wahrnehmung und Wissenschaft (Oreos, Waakirchen-Schaftlach, 2000) 13-34.

Traducido al español para "Anuario Filosófi co" XXXV/3 (2002) 713-730.

Republicado en R. Spaemann, Ética, política y cristianismo (Palabra, Madrid, 2007) 189-212. 
uando éramos niños hubo un instante en el que, cuando nos contaban una historia, hicimos la pregunta: “¿Esto ha sido real alguna vez?”. Esperábamos una respuesta sencilla a esta pregunta, por tanto, no una respuesta que extendiera la acepción del concepto "real" hasta el punto de que también se podrían incluir en él los cuentos de hadas y los sueños. Los sueños eran precisamente aquello que queríamos excluir con nuestra pregunta infantil. El que pregunta por la realidad siempre quiere excluir algo. Es que la realidad no es una característica que añada algo a lo que ya hay. Lo real se distingue de lo no real y si queremos saber lo que alguien quiere decir cuando pregunta por aquello que es real, tenemos que saber lo que quiere excluir como no real. Lo que excluimos puede tener muchos nombres: sueño, ficción, mentira, apariencia, figuración, constructo, realidad virtual, etc. La distinción entre ser y apariencia es la primera y más fundamental distinción con la que empezó la filosofía. Ahora bien, ya en los inicios de la filosofía surgió una oposición contra esta distinción, concretamente entre los llamados eléatas. Su argumento era sencillo: lo no real, es decir, lo no existente per definitionem no es. No existe lo que no existe. El sueño es tan real como lo es la vigilia y lo soñado como soñado de la misma manera como lo vivido en vigilia. Sea lo que fuera lo que distingue la realidad virtual de la no virtual, se llama al fin y al cabo como esta: "realidad".

La cuestión es si verdaderamente existe otra cosa que la realidad virtual. Con esta pregunta desconcertante estamos confrontados cada vez más en la actualidad. Cuando desaparece la oposición entre apariencia y ser, entonces es indiferente si decimos que todo es real o todo es apariencia. "Esse est percipi", decía George Berkeley. Y David Hume: "We never advance one step beyond ourselves". Si vivimos algo entonces es algo que hemos vivido precisamente nosotros. Transcurre dentro de nosotros. Si tal vez es originado de alguna manera desde el exterior, no somos capaces de averiguarlo. Incluso la idea de algo externo es a su vez solo una idea que toma prestada su metafórica de circunstancias espaciales que conocemos.Y también la idea de otro fuera de nosotros, la idea de algo que existe fuera de nuestro pensamiento mantiene, a pesar de 
todo, nuestra idea. La filosofía del siglo XIX ha traído y llevado esta reflexión hasta la saciedad.

El desarrollo de la técnica a finales del siglo XX lleva a cabo esta reflexión en la práctica. La simulación técnica no solo suplanta la realidad, pretende revelar su esencia. Los constructos cibernéticos ya no imitan solo lo vivo, pretenden explicarnos lo que es la vida. Que no es más que esta simulación. El onanismo o el cibersexo ya no son solo un sucedáneo de placer; se presentan como la cosa misma. "We never advance one step beyond ourselves". Ciertamente estamos construidos de tal manera que necesitamos al otro para nuestra felicidad. Pero, como para cualquier interpretación funcional, también para esta es válida la consecuencia: abre el margen para equivalencias funcionales. Una simulación del otro también hace sus veces. Si es perfecta, es el otro.

¿Pero lo es de verdad? ¿No existe un criterio para poder distinguir lo real de lo no real? ¿No existe una diferencia? Por supuesto que existe naturalmente una diferencia y es incluso la más importante de todas las diferencias. ¿Y un criterio? No, no existe. Pues la realidad no es, como decíamos, una propiedad. Max Scheler opinó que lo real se hace perceptible para nosotros a través de la resistencia. La experiencia de la realidad sería una experiencia de la resistencia. Pero no es cierto. También en los sueños experimentamos resistencia, amenaza, dominación. Y existen sueños en los que tenemos la conciencia refleja de no soñar, en los que hasta nos convencemos a través de experimentos empíricos de que no soñamos. A veces incluso el despertar es soñado. Soñamos que hemos soñado y que ahora nos despertamos. Ningún criterio, sino solo el despertar otra vez nos da una certidumbre sin criterio de que ahora estamos realmente despiertos. Y esto no cambia tampoco el hecho de que en el sueño tuvimos la misma certidumbre. La duda que deducimos de ello permanece puramente teórica. Es decir, no es una duda, sino solo la constatación de que nuestra certidumbre no se apoya en un criterio.

Por cierto, también existe el contrario, a saber, la duda de la realidad de lo soñado en el mismo sueño. Cuando tenía cinco años en sueños me perseguía una bruja. Corría detrás de mí en una calle 
del pueblo. Corrí lo que pude. La distancia se redujo constantemente. De repente me acordé que mi madre me había dicho que no había brujas. Mi madre decía siempre la verdad. Así le creí más que a las apariencias y mi conclusión fue: la bruja tiene que ser soñada. Solo debo tratar de despertar antes de que la bruja, cuyo aliento ya noto, me coja. Confiando en la palabra de mi madre me arrojé a la calle, di vueltas de un lado a otro y me desperté. No era un criterio empírico lo que hizo que la bruja fuese irreal. Era un acto de fe que hizo que me arriesgara a considerarla como irreal.

¿Pero qué significa real en este orden de ideas? ¿Cuándo algo no es soñado? Heráclito dijo: "En sueños cada uno tiene su propio mundo. En la vigilia tenemos un mundo único y común”. Si voy al monte con un amigo y en el camino nos tomamos algo en un refugio y más tarde se revela en una conversación con este amigo que nunca había dado conmigo un paseo semejante y al consultar al dueño del refugio se pone de manifiesto que en su refugio nunca había entrado nadie que se pareciera ni a mí ni a mi amigo, entonces este paseo debe haber sido soñado.

El mundo real, dije, es el mundo común. Esto puede malentenderse. Se puede entender como si únicamente fuera real aquello que haya sido vivido y reconocido realmente por todos. No puede ser así. Pues se sabe que hay hombres que cierran los ojos ante la realidad. Y existen, por ejemplo, en la astrofísica concepciones controvertidas acerca de lo que existe y no existe. Pero no diríamos, sin embargo, que la realidad surge exclusivamente a través del consenso sobre ella. No el consenso fáctico, sino la capacidad de consenso universal es característica de las aserciones verdaderas acerca de lo real. Y no consideramos algo verdadero porque lo consideramos capaz de generar consenso, sino que lo consideramos capaz de generar consenso porque es verdadero, por ejemplo, porque una oración corresponde a una realidad. Nuevamente se nos escapa, por tanto, lo que queremos decir con "real", o lo que queremos excluir con la palabra. Pues, como ya adelanté: apenas vamos a poder dar una definición positiva de la realidad. Solo podemos decir lo que queremos excluir con esta palabra. Queremos excluir en primer lugar el sueño, la figuración, por tanto, aquella forma de ser de una 
cosa que solo puede explicarse de modo endógeno, por tanto, como idiosincrasia de aquello que presenta la cosa o la circunstancia, o sea, aquello cuyo ser se agota en su ser como objeto. Los meros objetos no son reales, tampoco cuando existe consenso sobre ellos. Esto debe tenerse muy presente.

Imaginémonos a un hombre tumbado en su lecho de muerte. Es incapaz de exteriorizar de ninguna manera señales que permitan deducir lo que ocurre en él. A su alrededor se halla un equipo de médicos. Sobre la base de datos de medición los médicos están convencidos de que el paciente no tiene dolores y que ya no oye lo que se dice en su alrededor. Sin embargo, el paciente sí tiene dolores y oye también lo que los médicos dicen de él. Por tanto, sabe que están en un error, pero no puede expresarlo antes de que se muera. Supongamos que este caso sigue preocupando a la ciencia médica. De modo que vuelven a analizarse nuevamente los datos, pero al final la "scientific community" llega a la conclusión de que el hombre no había sido capaz de oír ni de sentir dolores en el momento en el que el equipo lo examinaba. Entre los hombres vivientes y particularmente entre los científicos existe, por tanto, un consenso unánime. Pero en este caso es un consenso acerca de lo falso. Pues lo que tuvo lugar realmente, solo lo sabía aquel que ahora ya no vive. Existe, por tanto, la verdad, pero nadie la sabe ya. El hecho de que solo yo vivo mis propios dolores no significa que sea únicamente verdadero para mí que tengo dolores. Cuando alguien dijera: "yo te vivo de una manera distinta a la que tú te vives, para mí no tienes dolores", yo le contestaría: "No importa en absoluto cómo tú u otra persona me viven o qué constataciones científicas alguien hace sobre mí. La verdad sobre mis dolores solo la puedo saber yo. Pero esta verdad no es por ello una verdad solamente para mí, sino para cualquiera". Se podría objetar que esta situación en la que un sujeto consciente de sí mismo se sabe objeto del saber de otros es un caso límite que no puede servir de modelo para nuestra relación con la realidad. Quisiera defender la tesis contraria: este caso es el paradigma de nuestra relación con la realidad y de nuestro concepto normal de la verdad. Déjenme explicarlo. 
En primer lugar, hemos de tener claro que el discurso de sujetos y objetos como dos ámbitos del ser fundamentalmente opuestos, pasa por alto la realidad. Dicho con más precisión: esta visión hace que desaparezca algo así como la realidad. Los objetos que solo son objetos no tienen más que un ser subjetivo. No hay diferencia si son soñados o se presentan ante la consciencia en vigilia puesto que no son nada más allá de su ser dados. ¿Pero podemos llamar "real" a algo como la pura subjetividad? El cogito cartesiano carece de contenido porque es instantáneo. La autocertidumbre absoluta de la conciencia solo es puntual, sin dimensiones, pues cuando se exprese ya ha pasado tiempo. Debería decirse, por tanto, "yo he pensado". Pero este recuerdo ya no es autoconsciencia inmediata, sino objetivación de uno mismo. Y esta objetivación de la propia subjetividad en el recuerdo es el presupuesto para que los sujetos puedan convertirse en objetos el uno para el otro, y esto como sujetos. No el cogito puntual, sin contenido, instantáneo es real; reales son los sujetos en tanto que sujetos objetivos transtemporales, es decir, como personas, como personas con una biografía que se constituye tanto desde el propio recuerdo como desde el recuerdo de otros. Las personas no son puntos de subjetividad instantáneos. La autoconsciencia instantánea es más bien el resultado de la reflexión de un sujeto, el resultado de una vuelta desde los muchos contenidos vividos hacia sí mismo. Lo primario no es, como observó Gottfried Wilhelm Leibniz, el cogito de Rene Descartes, lo primario es la vivencia: "varia a me cogitantur".

Pero todavía queda por fundamentar la tesis de que la forma de ser en que se dan las personas unas para otras es el paradigma de la forma de ser en que se da la realidad en sí. Quisiera preguntar primero, ¿cómo podemos conceder ser a aquello sobre lo cual hablamos, una realidad más allá de lo que es para nosotros lo encontrado y de cómo lo experimentamos? ¿Existe una base para ello en la experiencia misma? Sí, existe esta base y es la comunicación entre las personas. Las personas que se dan a entender mutuamente que ellas mismas son todavía algo más allá de lo que ostentan. El dolor del otro es algo distinto a su comportamiento doloroso visible para mí. Esta diferencia se convierte para nosotros en certidumbre 
absoluta allí donde nosotros mismos somos aquellos a los cuales y sobre los cuales se habla. Me parece que la pluralidad de personas tiene que ser configurada por al menos tres personas para que la subjetividad se vuelva objetiva, es decir, persona. En una conversación entre tres cada cual puede cambiar en cualquier momento la atención del interlocutor al objeto de la conversación. Y a su vez puede tomar postura acerca de lo que los otros dos han dicho de él. Pero cada uno es consciente de que él mismo se sitúa algo más allá de lo que los otros dos opinan de él. Podría imaginarme que el otro era solo un sueño. No puedo pensar de mí que solo soy el sueño de otro. Esta conciencia es la base de cualquier reconocimiento de realidad más allá de la objetividad. También formaba la base del concepto kantiano de una cosa en sí, que en la Crítica de la razón pura permanece vacío, pero que adquiere un contenido concreto en la Crítica de la razón práctica y no puede ser otro que: la libertad personal. Este paso de la experiencia de nosotros mismos a la experiencia de la realidad absoluta se nos hace comprensible de la forma más inmediata allí donde se trata de animales más evolucionados con un sistema nervioso central. Atribuimos subjetividad a estos animales. Por esta razón, los hombres hablan con los animales y por esta razón existen leyes de protección de animales que ponen límites a la objetivación sin escrúpulos de los animales. Los consideramos "reales", les concedemos "ser" más allá de su ser como objetos. No exigimos saber cómo es lo de ser un murciélago. Pero presuponemos que es de alguna manera ese ser murciélago, mientras que no es de ninguna manera el ser un coche. Es decir, concedemos ser al murciélago. Este ser que tiene en común con nosotros se llama "vida". La "vida", escribe Aristóteles, "es el ser de los seres vivos". La vida tal como la experimentamos nosotros mismos no es un determinado estado complejo de la materia. No me experimento como un estado de algo que no sea hombre. El hombre es, diciéndolo nuevamente con Aristóteles, sustancia viva, por tanto, realidad propia y primaria de la que pueden existir muchos estados, pero que en sí mismo no es un estado, sino portador básico y esencia de estados. Y así también, suponemos, el murciélago. Le concedemos vida, por tanto, ser él mismo. 
No es casualidad que en este orden de ideas se hable de conceder y reconocer. Ya vimos que "ser" en el sentido de "realidad" no es un dato empírico. No se impone. No existe criterio obligatorio para afirmar la realidad de la subjetividad. Ciertamente existen buenas razones para suponerla, es decir, para no considerarnos vivos solo a nosotros y existe por tanto una desaprobación moral de aquellos que niegan el reconocimiento a lo vivo como vivo. No se pueden separar la ontología y la ética. El amor y la justicia no son posibles bajo la premisa del solipsismo, esto es, bajo el supuesto de que los demás hombres y los demás seres vivos únicamente son mis sueños. El humanitarismo y la alegría en el trato con los animales no son posibles si los animales no viven y experimentan, es decir, si no es de alguna manera el ser un animal de esta o aquella especie.

Una conocida objeción reza: uno no debería considerar antropomórfica la vida extrahumana. Mi respuesta a ello es: tenemos que considerarla como antropomórfica si queremos hacerle justicia. Solo partiendo de la vida consciente que somos nosotros mismos, podemos hablar de modo adecuado de la vida inconsciente, de la vida extrahumana. No tenemos acceso directo a esta vida. Solo podemos considerarla vida consciente restando la consciencia. Descartes opinó: si quitamos la conciencia, la vida no es nada. Los cartesianos torturaron a los animales, consideraron sus expresiones de dolor como reacciones mecánicas. Pero esto no corresponde a nuestra experiencia. Cuando somos conscientes de que estamos de humor sereno, que tenemos hambre o ligeros dolores de cabeza, experimentamos este humor, esta hambre o estos dolores de cabeza como algo que ya tuvimos antes de que fuésemos conscientes de ello. No podemos contestar a la pregunta ¿qué era el hambre antes de que fuéramos conscientes de ella? Porque solo el hambre consciente nos es consciente. $\mathrm{Y}$ sin embargo, forma parte de esta conciencia que el hambre ya existía antes y que a través de la conciencia entra en una fase nueva. Antes era algo semejante al hambre consciente, por tanto, era hambre consciente menos la conciencia. $\mathrm{Y}$ así es correcto y es la única posibilidad de hablar antropomóficamente de la vida real, no humana, no consciente y de ser consciente, a la vez, de este antropomorfismo. 
La alternativa a este tan vilipendiado antropomorfismo en la biología es el antropocentrismo. El mundo moderno es antropocéntrico como ningún otro anterior. Tampoco la nueva concienciación medioambiental cambia nada. Al contrario: definiendo todo lo existente extrahumano como medio ambiente se aplica radicalmente al hombre. La protección de las especies tiene que ver algo con la conciencia medioambiental porque las especies naturales pertenecen a la riqueza de nuestro mundo. La protección de animales, en el fondo, no tiene que ver con esto porque se preocupa de los animales mismos. La ciencia moderna es antropocéntrica. No pregunta por lo que realmente es y lo que por esta razón tiene carácter de ser común [Mitsein] con nosotros, sino que pregunta por el modo en el que nos aparece como objeto y como lo podemos manipular. Conocer una cosa significa, ya lo escribió uno de los padres del pensamiento antropocéntrico de la ciencia moderna, Francis Bacon, "To know what we can do with it when we have it". Para saber lo que puedo hacer con una cosa no tengo por qué saber lo que es realmente, cómo es ella misma. Puedo, por tanto, renunciar al antropomorfismo a favor del antropocentrismo. Las cosas en tanto en cuanto son objetos puros, están opuestas al sujeto, no tienen nada en común con él. Querer comprender la realidad como tal significa contemplarla bajo el aspecto de una similitud mayor o menor con nosotros. La ciencia objetivadora es la que mejor conoce lo más distante de nosotros, el comportamiento de los elementos más sencillos de la materia inorgánica. E intenta comprender lo más próximo y también a nosotros mismos como combinación compleja sobre la base de estos elementos. Cuanto más compleja tanto más difícil es esta comprensión. El hecho de que de una combinación de esta índole haya surgido un cuarteto de cuerdas de Ludwig van Beethoven o las fórmulas de la teoría de la relatividad se sitúa en una oscuridad impenetrable. Si no queremos inventariar repertorios objetivos, sino comprender la realidad, el asunto se presenta de forma exactamente inversa: comprendemos el cuarteto de cuerdas o la teoría de la relatividad mejor de lo que comprendemos el hecho de ser una bacteria, en el caso de que de alguna manera sea un ser. Si no es así, ya no podemos comprender nada, sino únicamente registrar datos objetivos. 
Pues también para el mundo material inorgánico, alejado de nosotros se aplica la norma: contemplarlo como real, atribuirle algo así como un ser él mismo, significa contemplarlo bajo el aspecto de la similitud con nosotros, por tanto, de modo antropomórfico, no como objeto, sino como ser en comunidad [Mitsein]. El intento de renunciar a ello tiene una larga historia. Empieza con la renuncia programática a cualquier teleología en la contemplación de la naturaleza, por tanto, a cualquier idea de una orientación de los procesos naturales hacia una meta. Nuevamente ha sido Bacon quien ha declarado que tales contemplaciones serían tan infructuosas como las vírgenes consagradas a Dios. Los tiempos en los cuales se estimaban las vírgenes consagradas a Dios habían pasado para Bacon. La orientación hacia una meta presupone conciencia; eso es lo que se nos repite desde Johannes Buridan hasta Wolfgang Stegmüller. No se toleran tendencias inconscientes. Lo que quedó fue una causalidad sin rumbo, una causalidad de los efectos. Pero también esta se nos revela como antropomorfismo. Lo que es una causa lo sabemos primariamente desde la experiencia de nuestra propia actuación. Movemos nuestro brazo y la bola rueda. Bertrand Russell postuló, por esta razón, abandonar también el concepto de la causa. Lo que hay son las leyes del movimiento de la naturaleza. Pero al fin se reveló que también el movimiento es un concepto antropomórfico. La física moderna ha logrado objetivar el movimiento mediante el cálculo infinitesimal. Pero esto se logró a cambio de que desapareciera como movimiento y se disolviese en una secuencia infinita de estados estacionarios. Leibniz, uno de los inventores del cálculo infinitesimal ciertamente lo sabía. Sabía que la objetivación física del movimiento solo tiene como objeto un constructo. El movimiento real solo puede comprenderse si ponemos como base un conato, un afán. Pero lo que significa afán lo sabemos solo desde nuestra autoexperiencia. Si no la hacemos entrar en juego no alcanzaremos la realidad del movimiento.

Y lo mismo vale finalmente para lo movido. Movidos los cuerpos, las cosas constituyen unidades idénticas consigo mismas durante un determinado tiempo. Parece que Friedrich Nietzsche ha sido el primero en señalar que también la idea de tales unidades, por 
tanto, la idea de las cosas, es un antopomorfismo. Somos nosotros los que nos experimentamos como unidades, como unidades que conservan su identidad en el tiempo. Nos experimentamos como sujetos de la voluntad y de la acción responsables de sus actuaciones. Los niños golpean la mesa si han chocado contra ella. Pero de cierta manera lo hacemos todos en tanto en cuanto por cualquier motivo hablamos de las cosas. La idea del ser de algo es inseparable de la idea de la identidad de aquello que es. Y precisamente esta idea es un antropomorfismo fundamental. Sin embargo, si nos hemos desprendido una vez de las cosas tenemos que desprendernos también de nosotros mismos. La despedida del antropomorfismo es al fin y al cabo una despedida del hombre mismo, es decir, de la contemplación humana del hombre. El hombre se convierte en antropomorfismo para sí mismo. Es la última cosa que se disuelve. El resultado es un mundo sin sujeto e indiferente, un mundo de objetos que ya no son objetos de nadie. Desaparece la idea de realidad. Nietzsche ha perfeccionado la convicción de Hume: "We never do one step beyond ourselves". Se manifiesta así que la idea del yo a su vez ya presupone un paso más allá del yo, por tanto una autotrascendencia. Por cierto, Hume ya lo había visto. Declara abiertamente que él no podía contarse entre los hombres que gozan de un yo. Y eso porque el ser del yo no es un estado, ninguna propiedad empírica, sino que es aquello, o mejor dicho, aquel o aquella que se hallan en determinados estados empíricos. Pero para el empirismo solo existen estos estados. Por eso tampoco es una casualidad que los que aprueban el suicidio, el suicidio asistido y la eutanasia, proceden por regla general del ámbito del empirismo. Para ellos solo existen estados, deseables y no deseables. Los no deseables, es decir, los estados de sufrimiento, deben eliminarse, y si no hay otra posibilidad entonces a través de la eliminación de aquel que sufre. Pues el que sufre en el fondo no posee una realidad, un ser que fuera distinto de la totalidad de los estados en los que se encuentra. En el fondo, no es alguien que sufre, sino que es el sufrimiento que tiende a no ser. Y el complejo de estados tiende categóricamente a ello cuando el sufrimiento no es compensado por comodidades. En este caso es razonable eliminar la totalidad del complejo de estados. No nos en- 
gañemos. Las consecuencias de esta concepción todavía tropezarán con reacciones de defensa instintivas. La concepción misma recibe mientras tanto una aceptación amplia. Pero aquel que no es real para sí mismo, nada le es real. Para él solo existen estados, no el ser. A ello corresponde una sociedad como la propaga el neopragmático norteamericano Richard Rorty, una sociedad en la que no hay nada más importante que el placer y el dolor. De hecho, el placer y el dolor son modos de manifestación de la realidad de la vida que se realiza y aumenta o que es amenazada y peligra. En estos modos de manifestación se vive la vida. Platón analizó detenidamente la decadencia de una civilización en la que estos modos de manifestación se desconectan de aquello que se revela en ellas, por tanto, una sociedad de vivencias en la que solo importa la fabricación de vivencias y no lo que se vive, no la realidad. Una civilización de esta índole tiende a la autodestrucción. Es que hace que desaparezca la persona y solo deja sujetos de vivencia abstractos, sujetos sin dimensión temporal, sin identidad biográfica.

La fijación en el propio estado agradable, en el propio sentimiento no solo desatiende el sentido funcional de los estados, descuida sobre todo el carácter intencional de los sentimientos, por tanto, la realidad que se revela en el sentimiento. El bienestar, el placer de aquel al que le importa exclusivamente la sensación agradable y no algo que hace ilusión a uno, lo ilustra Sócrates una vez con la distracción de aquel que tiene sarna y por consiguiente siempre puede rascarse. Solo podemos provocar intencionalmente estados de placer corporal que son los más inferiores en tanto en cuanto que van unidos con la tristeza, la aflicción y la depresión. Con lo que se llama diversión también se puede uno evadir de sentimientos de vacío interior. No es una buena señal que la palabra "diversión" esté en auge hasta tal punto que recomiendan las misas por ser divertidas. La alegría es otra cosa que la diversión. La alegría tiene un contenido y varía con sus contenidos. La alegría causada por una mañana de primavera no es la misma que la que produce una partitura de Bach y esta no es la misma que la alegría generada por otra partitura de Bach. La alegría siempre es apertura a la realidad. Aquella apertura hacia la realidad que es completamente ade- 
cuada a la realidad la llamamos amor. El amor es el volverse real del otro para mí. En aquel amor que en el idioma de la tradición se llamaba "amor benevolentiae" el otro deja de ser medioambiente para mí, por tanto, un objeto tal vez importante, que aprecio y que tiene gran importancia para mí. En el amor nos damos cuenta que el otro es tan real como nosotros mismos y nos conocemos a nosotros mismos como parte del mundo del otro, de la misma manera que él forma parte de nuestro mundo.

Solo las personas pueden volverse reales para nosotros en este sentido último de lo real. Pero he llamado la atención sobre el hecho de que el ser, la realidad de personas no es conciencia, sino vida y que por esta razón todo lo vivo debe aceptarse como real. La bipartición cartesiana del mundo en conciencia y materia definida por la extensión ha conducido a una desrealización de la realidad, porque en ella ha desaparecido el eslabón intermedio que desde Platón informa el discurso sobre la realidad: la vida. El ser, la vida, el pensamiento eran la tricotomía clásica. Pero la vida era el paradigma propiamente dicho del ser. La conciencia se consideraba como aumento de la vida. "El que no conoce", escribe santo Tomás, "no vive completamente, sino que solo tiene media vida". La vida consciente es vida plena, por tanto, plena realidad. La vida inconsciente conserva un momento de indeterminación como los sentimientos inconscientes de los cuales se puede decir razonablemente que son menos reales que los claramente conscientes e incluso expresamente. Hay grados de realidad.

¿Pero qué pasa con el ser inferior a la vida? Un ser de esta índole se da en primer lugar dentro del conjunto de la vida, como medio ambiente, como alimento, como parte de nuestra alimentación, como material para la fabricación de un mundo de lo Zubandenen [lo que está a mano, al alcance] como lo llamó Martin Heidegger. Y existe como objeto de la física y la química. Tiene sentido hablar de una realidad de esta materia inorgánica más allá de lo que se nos muestra, por tanto, más allá de su objetividad. Ser y tiempo de Heidegger conoce este más allá solo como forma deficiente de la Zubandenheit [la propiedad de lo que está a la mano]. Lo que ha caído fuera de todas las relaciones vitales es lo "solamente presente". 
La categoría del "ser en comunidad" [Mitsein] no se considera aquí. ¿Pero está justificado? El pensamiento arcaico siempre considera el mundo inorgánico también como antropomórfico, por tanto, en análogo al orgánico. En los salmos se convoca al agua y al fuego para que alaben al Creador, san Francisco habla de los hermanos y hermanas al dirigirse a los elementos. Por cierto, siempre se trata de elementos, de cosas naturales, no de artefactos. Los artefactos son objetos, no concriaturas. No es de ninguna manera ser un coche, por tanto, un coche no puede alabar a Dios. A lo sumo, el hombre puede dar las gracias por ello. En la liturgia de la Iglesia católica se canta en la noche de pascua al bendecir el agua bautismal un largo discurso en el que se apela al agua. ¿Es un vestigio infantil? Es tal vestigio si decidimos considerar la materia inorgánica como irreal, por tanto, como algo que se agota estando a disposición de los seres vivos o como objeto de las ciencias. Si atribuimos al ser material una realidad en el sentido que venimos desplegando entonces le concedemos "ser-con" [Mitsein] y tenemos que admitir respecto de él, junto con el discurso antropocéntrico, también el antropomórfico como el más esencial.

El metafísico tal vez más importante del siglo XX, el matemático y físico inglés Alfred North Whitehead, ha desarrollado en el nivel de abstracción más elevado un discurso antropomórfico de esta índole. No se limitó a los antropomorfismos inconscientes e involuntarios que empleamos en cualquier momento al hablar de cosas, de identidad, de causas, de posibilidades, de movimiento o de pereza, es decir, cuando hablamos de veras. Él sabía que solo podemos hablar per analogiam, cuando se trata de entidades extrahumanas, sea de animales, sea de quantos. Cuanto más alejado de nosotros, tanto menos podemos decir lo que es el otro miembro de la analogía en sí mismo. Pero ya el hecho de que podamos hablar de un "en sí mismo" es un ejemplo del discurso análogo. Si no sabemos ni siquiera cómo es ser un murciélago, menos aún sabemos cómo es ser una partícula elemental. Pero Whitehead parte del hecho de que tiene que ser de algún modo, caso de que tengamos derecho de hablar de realidad. La realidad nunca es solo objetividad para sujetos y nunca meramente subjetividad sin contenido. Llamamos 
real a algo solo si tiene una especie de subjetividad, por muy rudimentaria que sea, y si esta subjetividad tiene un contenido objetivo, si "vive" algo. Expresiones como "tendencia", "plenitud", incluso "alegría" en relación con las entidades o acontecimientos reales elementales, las actual entities, como dice Whitehead, tienen que comprenderse naturalmente de tal forma que todo lo psicológico en sentido estricto se elimina de ellos, todo lo que podemos llenar con figuraciones imaginarias. En un sentido abstracto y formalizado similar, Leibniz ya había concedido "percepciones" a las mónadas de la especie inferior distinguiéndolas de apercepciones conscientes. ¿Qué significa esto? Apercepciones son efectos vividos. Pero lo que son realmente efectos de algo sobre algo, solo lo podemos pensar cuando partimos de impresiones vividas y entonces procedemos a eliminar la vivencia. Si queremos atribuir realidad a lo existente inorgánico solo podemos hacerlo determinando el ser de este existente como algo similar a la vida, de la que eliminamos determinados fenómenos característicos de la vida como el metabolismo. De la misma manera tenemos que comprender la vida como vida consciente de la cual restamos la consciencia. El ser real es "sercon" [Mitsein] o no es real.

En ello se esconde una paradoja. Hasta ahora pareció que el ontos on como dicen los griegos, es decir, lo realmente existente, es aquello que es como sí mismo y para sí mismo, por tanto, más allá de su objetividad para otros. El paradigma para el más allá de esta índole era nuestra autoexperiencia. Ahora bien, allí ya hay gato encerrado. Es que nosotros mismos no siempre sabemos mejor quiénes somos. Los otros pueden y tienen que ilustrarnos a menudo sobre nosotros mismos, empezando por el hecho de que nos cuentan nuestro nacimiento, que nos recuerdan acontecimientos que hemos vivido pero olvidado, hasta las interpretaciones de nuestro comportamiento en las que no podemos evitar reconocernos, a pesar de que tal vez nos resulte desagradable. Pero sobre todo: aquella autoconciencia que nos permite distanciarnos de todo, como lo que aparecemos a los otros no es pensable sin precisamente estos otros. Solo a través de otras personas aprendemos a actualizar nuestro propio ser como personas. Solo con la lengua surge la autoconsciencia y solo a través 
del reconocimiento como "alguien" a través de otros "álguienes" adquirimos una autoestima elemental o aquel amor propio natural y fundamental sin el cual no puede haber amor. Esto significa que a través de la mirada de otros nos volvemos visibles y reales para nosotros mismos. Lo real no es, por tanto, lo desvinculado, no es el eslabón aislado de una relación sacado de toda relación. Lo real existe solo en esta relación misma. La relación es lo propiamente real. Todas las entidades reales se hallan en una interacción. Reciben y son recibidas. "Todo lo que se recibe, se recibe según el modo del receptor", dice un adagio escolástico. Pero esto no significa que lo recibido es "modificado" en la recepción. La palabra "modificar" sugiere que una cosa tenía antes de su percepción otro aspecto que el que tiene en la concepción del perceptor. Esto presupone que la cosa tuviera antes de su percepción e independientemente de ella algún aspecto. Pero tener aspecto se refiere esencialmente a la vista. Así no tiene sentido hablar de figuras, cuerpos, dibujos, si no existe algo como la percepción de la configuración. Las configuraciones, pero también los dibujos en la superficie de reptiles, peces y pájaros a los que Adolf Portmann dedicaba tanta atención, son relativos a la existencia según la posible percepción. No tiene sentido decir que existe también más allá e independientemente de ello. En cambio, también la organización de los sentidos de los seres vivos es orientada hacia el hecho de percibir algo como configuración.

Ahora bien, sería equivocado interpretar relativistamente esta relatividad de lo existente, es decir, como si las configuraciones fuesen, según se dice, algo "exclusivamente subjetivo", algo construido por el perceptor. Lo que existe, son configuraciones y su percepción, colores y su percepción, números y su ser pensado, valores y su ser sentido. Ambos lados, sin embargo, tienen su realidad solo en esta relación recíproca. Por eso, no tiene sentido decir que las leyes de las matemáticas y de la lógica son productos de la psique humana como tampoco tiene sentido decir que estas leyes también existirían si no hubiera ningún pensamiento. Lo real es siempre la totalidad de esta estructura polar. Son reales los colores y sonidos, porque son reales el ver y el oír, pero ver y oír solo son reales porque son reales los colores y los sonidos. Es real cualquier acontecimiento de 
la oikeiosis, por muy efímero que sea, de la apropiación de un contenido objetivo por un polo subjetivo. Lo ignora el reduccionismo. Reduce un lado de la estructura polar al otro. Es monista. Así cree, por ejemplo, que una explicación de la teoría de la evolución podría decirnos lo que son la consciencia y el conocimiento. Pero estas explicaciones siempre son circulares. Presuponen las configuraciones, por ejemplo, la de un cerebro animal o humano, presuponen la causalidad. La mutación y la selección son procesos causales. Y luego reclaman estas categorías para explicar con ellas la percepción de la configuración y el origen de la categoría de la causalidad. La realidad de una estructura relacional de configuración, imagen y percepción se convierte en un procedimiento reduccionista declarando un lado de esta relación como epifenómeno y solo los demás como reales. Pero el precio de este reduccionismo es la circularidad, la tácita e inconsciente premisa de aquello que había que demostrar. Los miembros de esta relación son recíprocamente relativos. Pero la relación misma es lo real. Y el poder concebirla como lo real — esto es, concebir la realidad como realidad - es lo particular del hombre. Es la forma más elevada de actividad espiritual, autotranscendencia. Es una idea completamente falsa afirmar que algo se conoce de modo tanto más adecuado cuanto más pasivamente se comporta el perceptor. Lo sabemos de la relación mutua de los hombres. No puedo esperar aproximarme a la esencia de otro hombre si no invierto nada de la mía. Entonces permaneceré siempre en la superficie. Pero si invierto algo, si me entrego a mí mismo a esta relación, entonces el conocimiento llevará naturalmente los rasgos del perceptor, es un conocimiento muy personal. El conocimiento de la realidad no puede adquirirse de otra manera.

Este estado de las cosas se nos hace particularmente patente en la actualidad porque las artes plásticas modernas nos llaman la atención sobre ello. Permítanme que en este lugar, en la Academia Bávara de Bellas Artes, cierre con una mirada a las bellas artes y a su papel en una época en la que la realidad se desvanece. Durante siglos, mejor dicho, a partir del s. XVI el arte europeo era un arte ilusionista. Lo decisivo era la introducción de la perspectiva central en la pintura. Lo mismo se aplica a la arquitectura y la escultura. 
Las columnas de nuestras iglesias barrocas por regla general no son de mármol, sino que deben tener apariencia de mármol. Y las esculturas, por muy vivas que parezcan, a menudo son huecas y no tienen parte trasera. Fue el arte el que preparó el camino hacia la virtualización de la realidad. Pero el arte también es pionero en recordarnos lo que se ha perdido en este camino: precisamente la realidad. En un mundo cada vez más virtual, el arte se encarga de representar las joyas del ser. ¿Qué significado tiene cuando en una época de la reproducibilidad de la obra de arte, en la que el original se puede distinguir cada vez menos de la simulación, la autenticidad del original adquiere una importancia casi mágica, una importancia que solo es comparable con la "validez" de los sacramentos? Esta validez se basa en la realidad sensorial del tocar, que a su vez se basa en una secuencia ininterrumpida de imposiciones de manos hasta llegar a su fundador. La autenticidad de la obra de arte se basa en el tocar original de esta pieza de lienzo por este artista. En la corona imperial fundada en un conejo de pascua de Joseph Beuys; todo depende del hecho de que la historia ha pasado realmente. Porque no se puede mirar el conejo. En un mundo que cultiva las apariencias, el arte desempeña invirtiendo las relaciones tradicionales, el papel de la representación de la realidad, del ser que se ha retirado a la invisibilidad. O piensen ustedes en la barra cromada de unos 1.000 metros de largo que Walter De Maria ha hundido en la tierra con ocasión de una "documenta" [exposición de arte] en Kassel. Lo que se ve es el corte de la barra, un pequeño disco color de plata sobre el suelo. No es lo esencial lo que se ve, sino lo que importa es conocer la realidad de la barra hundida que solo es representada por este pequeño disco. Lo que importa es la actividad del observador que toma consciencia expresamente de lo que no ve. También aquí el arte se hace cargo de una función casi sacramental. Hace invisible una cosa para que se recuerde como real. En un mundo de fachadas, se encarga de representar la realidad perdida como invisible. Entregarse a la realidad significa entregarse a lo invisible. 